\section{On the Electron Drift Velocity in Solid Neon}

\section{Y. Sakai *, E.-H. Böttcher, and W. F. Schmidt}

Hahn-Meitner-Institut für Kernforschung Berlin, Bereich Strahlenchemie, Berlin

Z. Naturforsch. 37 a, 87-89 (1982); received December 29,1981

The electron drift velocity in solid neon is reported for the field strength range 1 to $50 \mathrm{kV} \mathrm{cm}-1$.

The electronic transport properties of solidified rare gases have received continuing interest since these materials represent the most simple solids. Detailed measurements of the electron drift velocity as a function of field strength were reported for sAr, sKr, and sXe by Miller, Howe, and Spear [1]. The low field mobilities were 1000, 3700, and $4500 \mathrm{~cm}^{2} \mathrm{~V}^{-1} \mathrm{~s}^{-1}$, respectively. In solid helium, on the other hand, Keshishev [2] reported mobilities of $10^{-5} \mathrm{~cm}^{2} \mathrm{~V}^{-1} \mathrm{~s}^{-1}$ or lower for the negative charge carrier. Although some unpublished data on solid neon of Spear's group have appeared in a later review [3], no data on the field dependence of the electron drift velocity in $\mathrm{sNe}$ have been published so far. Recently, interest in the application of solid neon as detection medium in ionization chambers for high energy physics has developed [4]. During our investigation of the transport properties of excess lectrons in liquid neon we also measured the electron drift velocity in solid neon. These results are presented here.

The experimental set-up has been described in detail already [5]. Excess electrons were injected into the solid neon by illumination of a metal cathode of a diode cell with a strong light pulse from an excimer laser. The pulse duration, approximately $8 \mathrm{~ns}$, was short compared to the drift time of the electrons.

An example of the photocurrent as a function of time is shown in Figure 1. The yield of injected

\footnotetext{
* On leave from Dept. Electr. Eng., Hokkaido University, Sapporo, Japan.
}

Reprint requests to Dr. Y. Sakai, Hahn-Meitner-Institut f. Kernforschung Berlin, Bereich Strahlenchemie, Postfach 3901 26, 1000 Berlin 39. electrons, as determined by integrating these curves, rose almost linearly to approximately $2 \%$ of the vacuum yield at $50 \mathrm{kV} / \mathrm{cm}$.

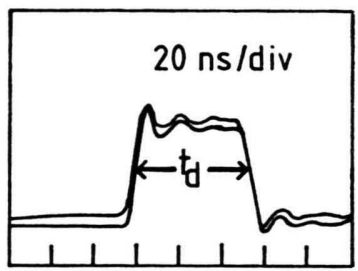

Fig. 1. Oscilloscopic trace of the photocurrent signal in solid neon at $8.75 \mathrm{kV} / \mathrm{cm}$.

The electron drift velocity as a function of the applied electric field is given in Figure 2. Below $1 \mathrm{kV} \mathrm{cm}^{-1}$ no data could be obtained since the signal to noise ratio became too small. In the range of field strength from $1 \mathrm{kV} \mathrm{cm}^{-1}$ to $50 \mathrm{kV} \mathrm{cm}^{-1}$ a sublinear dependence of $v_{\mathrm{d}}$ on $E$ is observed, which is indicative of hot electron effects. Above $30 \mathrm{kV} \mathrm{cm}^{-1}$ the drift velocity saturates and the value of $v_{\mathrm{ds}}=$ $1.9 \times 10^{6} \mathrm{~cm} \mathrm{~s}^{-1}$ is in line with the values of $\mathrm{sAr}$ $\left(1.07 \times 10^{6}\right)$, sKr $\left(0.76 \times 10^{6}\right)$, and $\mathrm{sXe}(0.56 \times$ $\left.10^{6}\right)$. For values of the electric field strength smaller than $1 \mathrm{kV} \mathrm{cm}^{-1}$ the dependence was extrapolated according to the behavior of solid argon and taking into account a low field mobility value of $\mu_{0}=$ $600 \mathrm{~cm}^{2} \mathrm{~V}^{-1} \mathrm{~s}^{-1}$ as quoted by Spear et al. [3].

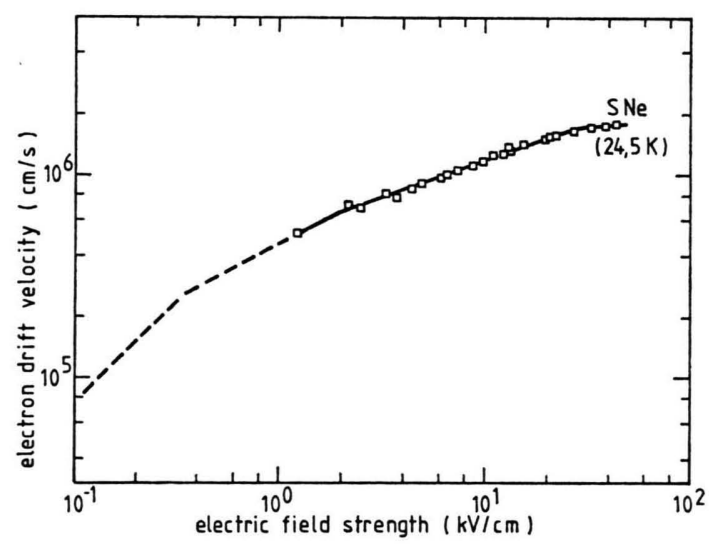

Fig. 2. The field dependence of the electron drift velocity in solid neon (24.5 K).

0340-4811 / 82 / 0100-0087 \$01.00/0. - Please order a reprint rather than making your own copy. 
[1] L. S. Miller, S. Howe, and W. E. Spear, Phys. Rev. 166, 871 (1968).

[2] K. O. Keshishev, Sov. Phys. JETP 45(2), 273 (1977).

[3] W. E. Spear and P. G. LeComber, Chapter 18 in "Rare Gas Solids", M. L. Klein and J. A. Venables, eds., Vol. 2, Academic Press, New York 1977, pp. 1119.
[4] V. Brisson, Ch. Gregory, J. Morinand, and P. Petian, Phys. Scripta 23, 688 (1981).

[5] Y. Sakai, H. Böttcher, and W. F. Schmidt, J. Electrostatics (1982), in press, and Proc. 7. ICDL, p. 46, Berlin, July 1981, IEEE Rep. No. 81 CH 1594-1. 
Fluorescence Spectra of Lightly and Heavily Doped $\mathrm{NH}_{4} \mathrm{Cl}: \mathrm{Tl}$

B. S. Prasada Reddy, R. V. Joshi, L. H. H. Prasad, and T. R. Joshi

Department of Applied Physics, Faculty of Technology and Engineering, M.S. University of Baroda, Baroda, Pin. 390001, India

Z. Naturforsch. 37 a 89-90 (1982);

received October 15,1981

The excitation and emission spectra of pure and thallium activated ammonium chloride have been examined at room temperature. It is found that excitation bands at 242 and $256 \mathrm{~nm}$ and emission bands at 380 and 460 as well as $500 \mathrm{~nm}$ are characteristics of lightly and heavily doped $\mathrm{NH}_{4} \mathrm{Cl}: \mathrm{Tl}$, respectively. It is suggested that internal electronic transitions in $\mathrm{TlCl}$ molecules and $\left(\mathrm{TlCl}_{n}\right)^{-}$complex ions are responsible for the two emission band groups.

The thallium doped alkali halides $\mathrm{NaCl}: \mathrm{Tl}$ and $\mathrm{KCl}: \mathrm{Tl}$ have been investigated in great detail $[1-7]$. Less is known about the excitation and emission spectra of the ammonium halides. The main purpose of the present paper is to examine the fluorescence characteristics of lightly and heavily doped $\mathrm{NH}_{4} \mathrm{Cl}: \mathrm{Tl}$ phosphors. Attempts have also been made to suggest fluorescence centres for the emissions observed.

Analar grade ammonium chloride powder was obtained from the $\mathrm{BDH}$ laboratory, Chemical Division, Glaxo Laboratories, India. Crystallization from aqueous solution was used to prepare microcrystalline $\mathrm{NH}_{4} \mathrm{Cl}$ : $\mathrm{Tl}$ samples of concentrations $10^{-4}$ and $10^{-1} \mathrm{~m}$.f. of impurity thallium. The excitation and emission spectra were recorded at room temperature by means of an Aminco-Bowman Spectrophotofluorometer supplied by the American Instrument Co. Inc.

Typical excitation and corresponding emission spectra of pure $\mathrm{NH}_{4} \mathrm{Cl}$ and $\mathrm{NH}_{4} \mathrm{Cl}$ :Tl specimens with $10^{-4} \mathrm{~m}$.f. and $10^{-1} \mathrm{~m}$.f. of impurities are shown in Fig. 1A and 1B. A comparison of the spectra of pure $\mathrm{NH}_{4} \mathrm{Cl}$, lightly and heavily doped $\mathrm{NH}_{4} \mathrm{Cl}$ : $\mathrm{Tl}$ specimens brings about the following features:

(i) Introduction of thallium impurity enhances the fluorescence substantially.

Reprint requests to T. R. Joshi, Department of Applied Physics, Faculty of Technology and Engineering, M.S. University of Baroda, Baroda Pin. 390001, Indien. (ii) The lightly doped $\mathrm{NH}_{4} \mathrm{Cl}: \mathrm{Tl}\left(10^{-4}\right.$ m.f. $\left.\geqq \mathrm{Tl}\right)$, specimen displays a dominant excitation band at $242 \mathrm{~nm}$ with a corresponding emission peak at $380 \mathrm{~nm}$.

(iii) The excitation band at $242 \mathrm{~nm}$ shifts to $246 \mathrm{~nm}$ in heavily doped $\mathrm{NH}_{4} \mathrm{Cl}$ : $\mathrm{Tl}\left(10^{-1} \mathrm{~m} . \mathrm{f}\right.$.). The corresponding emission exhibits a new emission in the visible region around $460 \mathrm{~nm}$ along with the dominant one at $380 \mathrm{~nm}$.

(iv) The most striking feature of the heavily doped $\mathrm{NH}_{4} \mathrm{Cl}$ : $\mathrm{Tl}$ specimen is the appearence of an additional well defined excitation band around $256 \mathrm{~nm}$ with corresponding emissions at around 460 and $500 \mathrm{~nm}$. The emission at $380 \mathrm{~nm}$ appears as hump.

According to present understanding the luminescent centres comprise of an emitter (inherently present or deliberately introduced impurity) and a

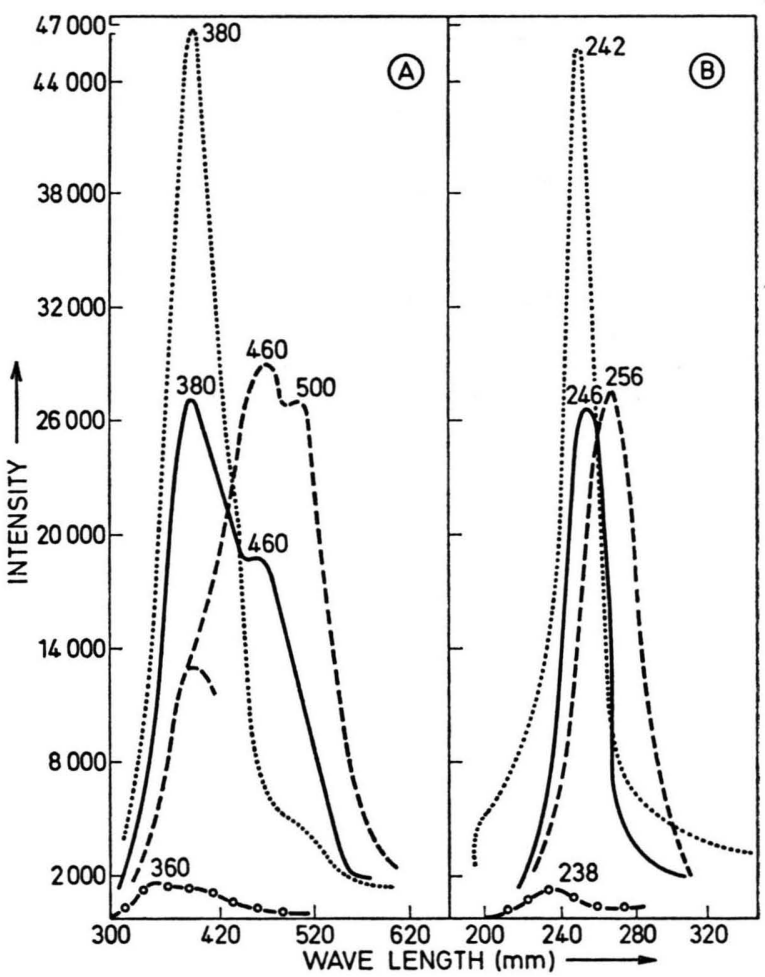

Fig. 1. (A) Emission Spectra, (B) Corresponding excitation spectra. - $-\mathrm{O}-\mathrm{O}-\mathrm{O}-$ pure $\mathrm{NH}_{4} \mathrm{Cl}, \ldots . .$. ... lightly doped $\mathrm{NH}_{4} \mathrm{Cl}$ : $\mathrm{Tl}$ (Tl concentration $10^{-4}$ m.f.), - and ---- heavily doped $\mathrm{NH}_{4} \mathrm{Cl}$ : $\mathrm{Tl}\left(10^{-1}\right.$ m.f. of $\mathrm{Tl}$ impurity) for near ultraviolet and visible emissions, respectively. 
trapping site (a point defect in the host lattice). The electron-hole recombination at the emitter without multiple trapping leads to the temperature independent spontaneous emission known as fluorescence. Thus we suppose that the luminescence emission is characteristic of the impurity irrespective of host lattice. It is believed that doping of $\mathrm{NH}_{4} \mathrm{Cl}$ with thallium generates a large number of isolated $\mathrm{Tl}^{+}$ions, $\mathrm{TlCl}$ molecules and $\left(\mathrm{TlCl}_{n}\right)^{-}$complexes whose relative concentrations depend on the concentration of the thallium impurity. The introduction of $10^{-4} \mathrm{~m}$.f. of $\mathrm{Tl}$ impurity in $\mathrm{NH}_{4} \mathrm{Cl}$ causes the prominent $380 \mathrm{~nm}$ emission band on $242 \mathrm{~nm}$ excitation (Figure 1). As it has been reported that the emissions around $320 \mathrm{~nm}$ and $380 \mathrm{~nm}$ are associated with $\mathrm{Tl}+$ ions and $\mathrm{TlCl}$ molecules, respectively [3, 7], it is suggested that, like in Tl-activated alkali halides, internal electronic transitions in undissociated $\mathrm{TlCl}$ molecules are mainly responsible for the $242 \mathrm{~nm}$ excitation and corresponding $380 \mathrm{~nm}$ emission in the case of lightly doped $\mathrm{NH}_{4} \mathrm{Cl}$ : Tl. The mechanism of fluorescence suggested for this emission is an excitation induced electron transfer from

[1] D. Curie, Luminescence in Crystals. John Wiley and Sons, New York 1953.

[2] J. S. Dryden and J. S. Cook, Proc. Phys. Soc. 80, 479 (1962). - J. S. Dryden, J. Phys. Soc., Japan 18, Suppl. 3, 129 (1963).

[3] F. Seitz, Chem. Phys. 6, 150 (1938).

[4] S. C. Sen and H. M. Bose, Z. Physik 167, 20 (1962). a halide ion $\left(\mathrm{Cl}^{-}\right)$to a neighbouring $\mathrm{Tl}^{+}$ion and recombination with it.

It is further suggested that increasing concentrations of thallium create substantial amounts of $\left(\mathrm{TlCl}_{n}\right)^{-}$complex ions along with $\mathrm{TlCl}$ molecules, influencing the $\mathrm{TlCl}$ molecules and causing the shift in the $242 \mathrm{~nm}$ excitation band to $246 \mathrm{~nm}$ (Figure 1B). On the other hand, the heavily doped specimens should display new emissions associated with the $\left(\mathrm{TlCl}_{n}\right)^{-}$complex ions themselves. The appearence of the 460 and $500 \mathrm{~nm}$ emissions along with the dominant $380 \mathrm{~nm}$ emission strengthens this expectation. Figure 1 (dashed lines) demonstrates the favourable excitation band at $256 \mathrm{~nm}$ for the 460 and $500 \mathrm{~nm}$ visible emissions. It is proposed from the present experimental results that both the $\mathrm{TlCl}$ molecule and $\left(\mathrm{TlCl}_{n}\right)^{-}$complex ions are present in $\mathrm{NH}_{4} \mathrm{Cl}: \mathrm{Tl}$ phosphor and that internal electronic transitions in the complex ions $\left(\mathrm{TlCl}_{n}\right)^{-}$are mainly responsible for the visible emissions. The fluorescence mechanism for the visible emission is more or less similar to that suggested for the $380 \mathrm{~nm}$ emission.

[5] D. A. Patterson and C. C. Klick, Phys. Rev. 105, 401 (1957). - D. A. Patterson and H. W. Etzel, Phys. Rev. 112, 1112 (1958). - D. A. Patterson, Phys. Rev. 112, 296 (1958).

[6] J. Ewles and R. V. Joshi, Proc. Roy. Soc. A 254, 358 (1960).

[7] R. V. Joshi and L. H. H. Prasad, J. Lum. 15, 105 (1977). 